Ian Christian A. Gonzales, MD

Cagayan de Oro Consortium of Otorhinolaryngology Head and Neck Surgery Northern Mindanao Medical Center
Correspondence: Dr. Ian Christian A. Gonzales Cagayan de Oro Consortium of Otorhinolaryngology Head and Neck Surgery

Northern Mindanao Medical Center

Capitol Compound, Cagayan de Oro City 9000

Philippines

Phone: (6388) 726362 local 636

Email: ianchristiangonzales@gmail.com

The author declares that this represents original material, that the manuscript has been read and approved by the author, that the requirements for authorship have been met by the author and that the author believes that the manuscript represents honest work.

Disclosures: The author signed a disclosure that there are no financial or other (including personal) relationships, intellectual passion, political or religious beliefs, and institutional affiliations that might lead to a conflict of interest.

\section{(c) (1) $\Theta \odot$}

\title{
Lethal Midline Granuloma in a 15-Year-Old Girl: A Diagnostic Dilemma
}

\begin{abstract}
Objective: To report a case of lethal midline granuloma and discuss the diagnostic and treatment dilemma and management.
\end{abstract}

\section{Methods:}

$\begin{array}{ll}\text { Design: } & \text { Case Report } \\ \text { Setting: } & \text { Tertiary Government Hospital } \\ \text { Patient: } & \text { One }\end{array}$

Results: A 15-year-old girl under treatment for pulmonary tuberculosis presented to the Emergency Room for epistaxis and a nasopalatine lesion. She was managed as a case of nasopalatine osteomyelitis for one month and discharged on antibiotics. She returned due to bleeding after being lost to follow up for 3 more months. Hemostasis, debridement and biopsy yielded atypical cells, possibly lymphoma. Immunohistochemistry confirmed the diagnosis of NK-cell lymphoma. Unfortunately, she expired prior to initiation of chemotherapy.

Conclusion: Clinicians must have a high index of suspicion for lethal midline granuloma in chronic, non-healing midline lesions. Multiple biopsies confirm the diagnosis and earlier initiation of treatment may improve prognosis.

Keywords: Granuloma, lethal midline; Lymphoma, extranodal NK-T-cell

Lethal midline granuloma is a rare clinical entity ${ }^{1}$ that usually occurs among middle-aged men in the Southeast Asian and South American region ${ }^{2}$ with only a few documented cases in the Philippines. ${ }^{3}$ With informed consent from her parents and her assent, we report its presentation in a young girl and discuss the diagnostic and treatment dilemma and management involved.

\section{CASE REPORT}

A 15-year-old girl presented to the ear, nose, throat (ENT) emergency room (ER) of the Northern Mindanao Medical Center with a chief complaint of epistaxis and a nasopalatine lesion. Nine months prior to admission, she noted nasal pruritus and occasional discomfort of the hard palate. No consultations were made and no medications were taken.

Two months before admission, she was brought to a local health center for nonproductive cough associated with undocumented fever and weight loss. Direct sputum smear microscopy 
was positive for acid-fast bacilli and Category I Anti-tuberculosis (TB) treatment was started using the Directly Observed Treatment-Short Course (DOTS) protocol with good compliance. She did not reveal that she already had a nasopalatine lesion at this time.

She developed increasing nasal congestion over the next month and had epistaxis the day before, prompting consult and subsequent admission. She had no previous hospitalization or surgery and no history of any heredofamilial disease.

Baseline vital signs were within normal limits. She was asthenic with a BMI of $11.41 \mathrm{~kg} / \mathrm{m}^{2}$. Clinical examination revealed an extensively ulcerated and necrotic lesion on the hard and soft palate with a perforation that communicated with the nasal cavity. (Figure 1) Diagnostic nasal endoscopy revealed a perforation of the inferior to mid- nasal septum with erosion and ulceration of the nasal floor and inferior turbinate and minimal purulent discharge. The rest of the physical exam findings were unremarkable.

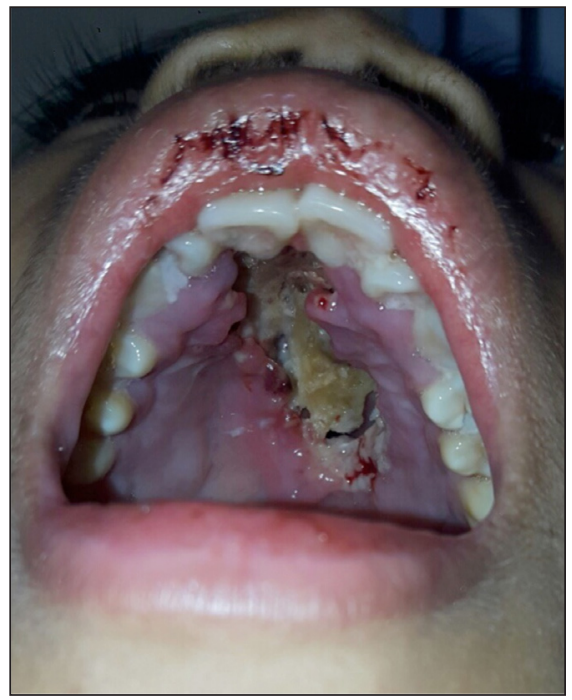

Figure 1. Intraoral view upon initial presentation.

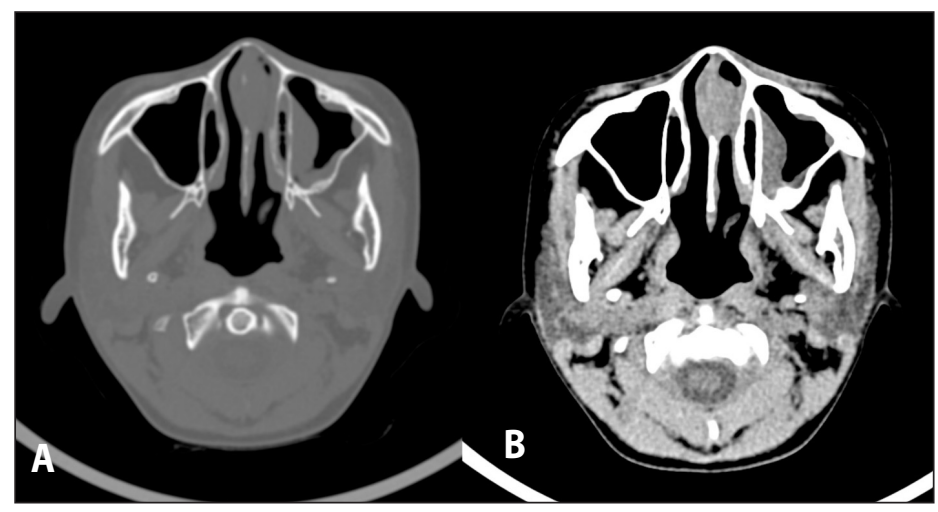

Figure 2. Initial CT scan, axial view, A. bone window (left), showing the septal mass extending to the left intranasal area, and B. soft tissue window (right), showing the septal mass extending to the left intranasal area.
She was anemic (RBC $2.46 \times 10^{6} / \mathrm{uL}$, hemoglobin $5.5 \mathrm{~g} / \mathrm{dL}$, hematocrit $17.4 \%$ ) with leukocytosis (WBC $15.93 \times 10^{3} / \mathrm{uL}$ ), neutrophilia (89\%) and lymphocytopenia (7.1\%). Contrast-enhanced computed tomography (CT) scan showed central, lobulated, soft tissue densities in both nasal cavities with partial lysis of the septum, hard palate and turbinates.

(Figure 2A, B)

Initial aerobic wound culture showed light growth of Pseudomonas putida, sensitive to multiple antibiotics. Blood cultures were negative. Nasopalatine swab was negative for acid-fast bacilli (AFB) and potassium hydroxide $(\mathrm{KOH})$ stain. Sputum AFB, GeneXpert and TB culture were negative. The patient was initially managed as a case of nasopalatine osteomyelitis. Clindamycin was started, anti-TB meds were continued, and she was co-managed by the pediatric infectious disease service.

Repeat wound culture a month later showed heavy growth of Stenotrophomonas maltophilia, sensitive to trimethoprim/ sulfamethoxazole. Repeat blood cultures were negative. Repeat

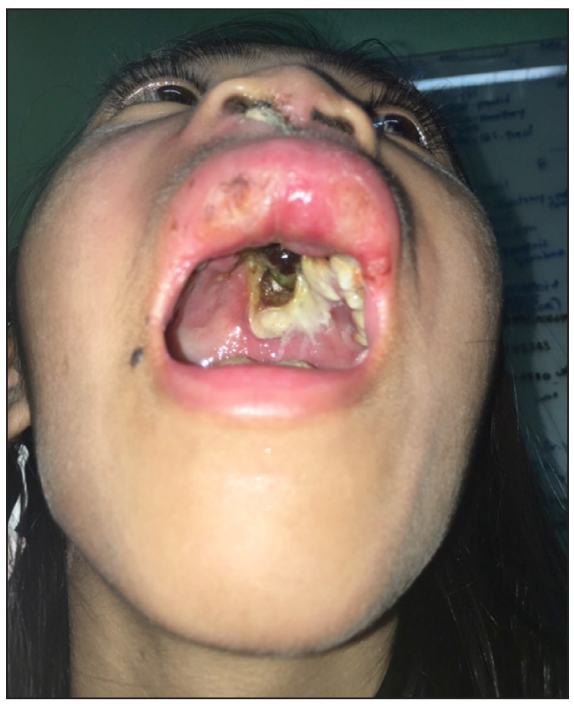

Figure 3. Intraoral view 3 months after initial presentation

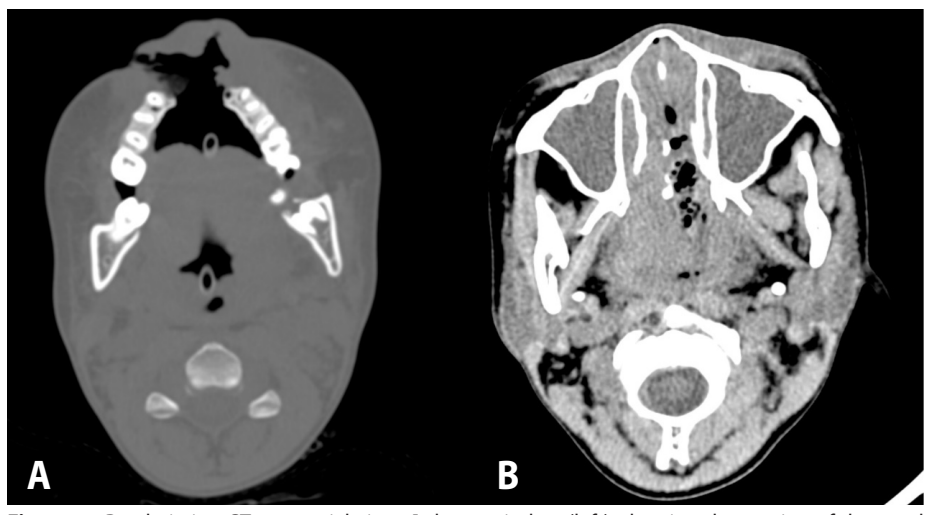

Figure 4. Readmission CT scan, axial view, A. bone window (left), showing destruction of the nasal and philtrum soft tissue, hard palate, alveoli, and dental structures; B. soft tissue window (right), showing destruction of the nasal septum, and extension of the mass to the nasopharynx, and bilateral maxillary sinusitis. 


\section{CASE REPORTS}

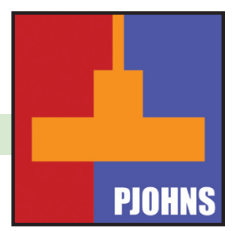

nasopalatine swab was also negative for AFB but positive for budding cells and pseudohyphae. A biopsy only showed granulation tissue with focal mild acute and chronic inflammation and necrosis. After three weeks, a more extensive biopsy with debridement and sequestrectomy under general anesthesia also showed chronic inflammation on histopathology. She was discharged on antibiotics and was subsequently lost to follow-up.

After 3 months, she presented at the ER for bleeding. The lesion had progressed anteriorly with necrosis and loss of the philtrum, columella, inferior and middle turbinates and nasal septum. (Figure 3, 4 A, B) She underwent emergency debridement and ligation of bleeders with preand post-operative blood transfusions. (Figure 5)

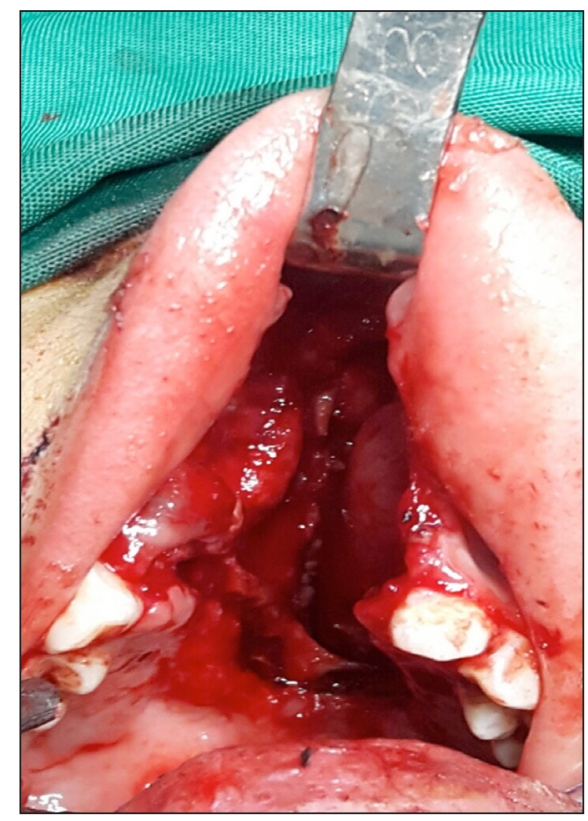

Figure 5. Intraoral view after debridement.

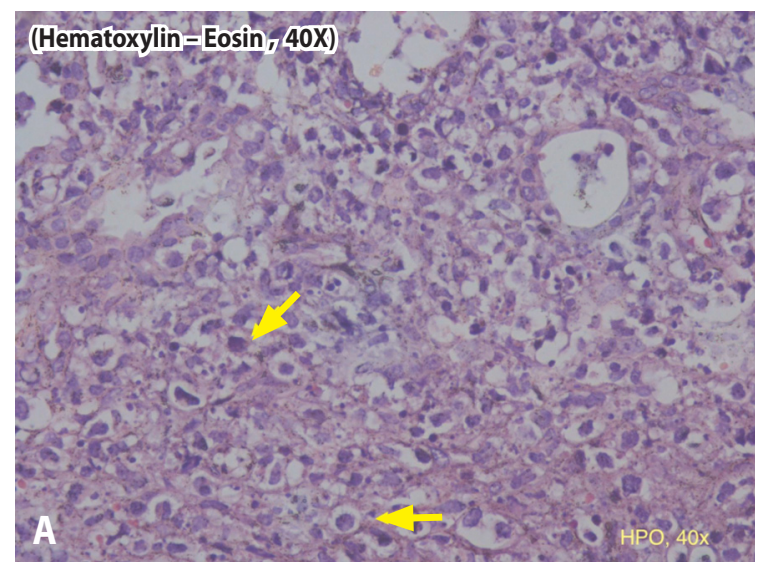

Figure 6A. Hematoxylin and Eosin stained slide showing atypical cells (arrows), suggestive of lymphoma, high power view, 40x magnification.

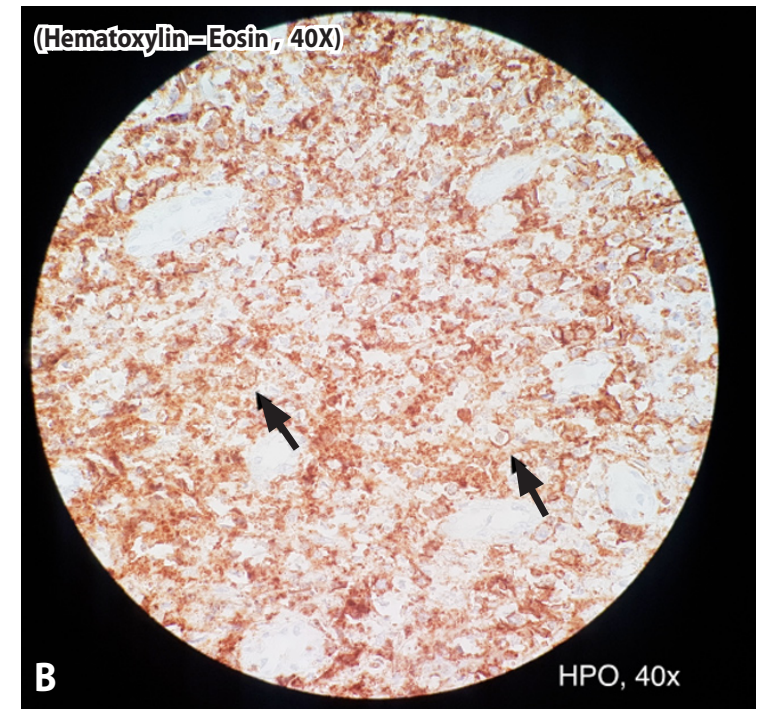

Figure 6B. HCD-56 immunohistochemical stained slide showing the NK-cells (yellow arrows), high power view, 40x magnification.

Histopathology of the intraoperative biopsy specimens showed atypical cells, suggestive of lymphoma. (Figure 6A) Immunohistochemical stains (CD3, CD20, cytokeratin, synaptophysin, chromogranin) were negative except for CD56, confirming diagnosis of NK-cell lymphoma. (Figure 6B) She was referred to Family and Community Medicine for counseling and supportive care and to Pediatric Oncology for chemotherapy but expired due to sepsis and bleeding.

\section{DISCUSSION}

Lethal Midline Granuloma is a rare clinical entity. ${ }^{1}$ McBride first described the term in 1897, after which it was also known as Stewart's Granuloma and Polymorphic Reticulosis. 'These previous terminologies were generic and confusing because the entity described is actually a heterogeneous group of disorders. ${ }^{2}$ Hence, it was subsequently recommended that the label 'Lethal Midline Granuloma' be used as a descriptive designation until a specific diagnosis is obtained.

Ishi et al. first recognized the presence of tumor cells expressing CD3 and termed the disease 'nasal T-cell lymphoma.' ${ }^{3}$ However, Suzumiya et al. noted that tumor cells in nasal lymphoma stained positive with cytoplasmic CD3 and CD56, but not T-cell receptors, suggesting an NKcell origin. ${ }^{4}$ The combined term 'Extranodal NK/T-cell Lymphoma' was adopted to take this into account.'

The differential diagnosis includes squamous cell carcinoma, other lymphomas, Wegener granulomatosis, infections or idiopathic which is then labeled as Idiopathic Midline Destructive Disease. ${ }^{5}$

The NK/T-cell lymphoma type of lethal midline granuloma is strongly associated with Epstein-Barr virus infection with a higher prevalence in 


\section{CASE REPORTS}

Philippine Journal Of Otolaryngology-Head And Neck Surgery

Vol. 33 No. 2 July - DeCEMBER 2018

PJOHE

South-East Asia, Central and South America, and it commonly occurs in middle-aged persons and affects males more frequently. ${ }^{2}$ Due to its rarity, exact incidence is unknown. At the Northern Mindanao Medical Center, this is only the second documented case. ${ }^{6}$

According to Gourin, ${ }^{7}$ the patient will initially present with nasal congestion, epistaxis and pain. As the disease progresses, necrosis, tissue loss and bleeding are noted. Secondary infection with bone sequestration is frequent, thus purulent discharge is expected. Systemic symptoms such as fever and weight loss are present only in advanced stages. $^{7}$

The working impression for this case was osteomyelitis vs. TB due to the patient's history of an ongoing TB infection along with the clinical appearance of the lesion on initial presentation. Exhaustive diagnostics for TB as well as other cultures and preliminary biopsies were either negative or inconclusive. Due to lack of clinical improvement, repeated biopsies were needed with more tissue from multiple sites and a greater portion of clinically normal-looking tissue. However, the patient was lost to follow-up for three months. Even when adequate biopsy specimens had been obtained, the unavailability of immunostaining in our institution and the expense of sending the specimens to another institution caused additional delays in clinching the diagnosis. Definitive diagnosis requires some combination of histopathological, immunohistochemical, and molecular studies, often only after repetitive biopsies have been obtained. ${ }^{3}$

Histologically, NK-cell lymphoma is characterized by polymorphic inflammatory infiltrates. ${ }^{5}$ Necrosis favors the entrance of infectious processes that can lead to sepsis. ${ }^{8}$ On immunostaining, the malignant tumor cells express CD2, cytoplasmic CD3 and CD56. In some instances, they may also express cytotoxic granular-associated proteins, granzyme $B$, perforin and $T$ cell-restricted intracellular antigen (TIA-1). ${ }^{2}$

Nasal NK/T cell lymphoma has a long natural history with an average of 29 months reported in all races. ${ }^{8}$ It has a very high mortality reaching almost $100 \%$ if untreated due to sepsis, hemorrhage or intracranial spread. ${ }^{9}$ It is usually responds to radiation and chemotherapy with the best clinical outcomes achieved when treatment is started early in the course of the disease. The chemotherapeutic regimens used in published case reports are CHOP (cyclophosphomide, doxorubicin, vincristine, and prednisone), SMILE (steroid [dexamethasone], methotrexate ifosfamide, L-asparaginase and etoposide) ${ }^{10}$ and AspaMetDex (L-asparaginase, methotrexate and dexamethasone). ${ }^{11}$ Other treatment options include autologous or allogenic hematopoietic stem-cell transplantation (HSCT) for advanced cases when remission is achieved. ${ }^{12}$ Local recurrence occurs in $50 \%$ of cases and overall prognosis is poor, with a 5 -year survival rate of $10 \%$ to $45 \%$ depending on the series. ${ }^{13}$

Our unfortunate experience taught us that clinicians must have a high index of suspicion for chronic, non-healing midface lesions as they are often incorrectly diagnosed as infection. Repeat biopsies must be done with access to advanced diagnostics such as immunohistochemical staining in order to clinch the diagnosis. The patient's financial situation is a serious consideration in the diagnostic delay, therefore we must advocate for better health care access and universal coverage. Although the prognosis is poor, aggressive treatment of secondaryinfections and subsequent chemoradiotherapy give the best possible chance of survival.

\section{ACKNOWLEDGEMENTS}

The author acknowledges the assistance of Drs. Maximo Saavedra and Edel Vivas of the Department of Pathology, Northern Mindanao Medical Center; and Dr. Alessandra Mallari of the Department of Pathology, Perpetual Succour Hospital with technical aspects of this report; and the consultants, residents and staff of the Department of Otolaryngology - Head and Neck Surgery and the Department of Pediatrics, for their contributions to patient care.

\section{REFERENCES}

1. Metgud RS, Doshi JJ, Gaurkhede S, Dongre R, Karle R. Extranodal NK/T-cell lymphoma, nasal type (angiocentric T-cell lymphoma): A review about terminology. J Oral Maxillofac Pathol. 2011 Jan; 15(1):96-100. DOI: 10.4103/0973-029X.80016; PMID: 21731288 PMCID: PMC3125667.

2. Tlholoe MM, Kotu M, Khammissa RA, Bida M, Lemmer J, Feller L. Extranodal natural killer/T-cell lymphoma, nasal type: 'midline lethal granuloma.' A case report. Head Face Med. 2013 Jan 17; 9:4. DOI: 10.1186/1746-160X-9-4; PMID: 23327615 PMCID: PMC3564726.

3. Ishii Y, Yamanaka N, Ogawa K, Yoshida Y, Takami T, Matsuura A, et al. Nasal T-cell lymphoma as a type of so-called "lethal midline granuloma." Cancer. 1982 Dec 1; 50(11):2336-44. PMID: 6754065.

4. Suzumiya J, Takeshita M, Kimura N, Kikuchi M, Uchida T, Hisano S, et al. Expression of adult and fetal natural killer cell markers in sinonasal lymphomas. Blood. 1994 Apr 15; 83(8):2255-60 PMID: 8161791.

5. Rodrigo JP, Suarez C, Rinaldo A, Devaney K, Carbone A, Barnes L, et al. Idiopathic midline destructive disease: fact or fiction. Oral Oncology. 2004 Oct; 41:340-348. DOI: 10.1016/j. oraloncology.2004.10.007; PMID: 15792605.

6. Chavez R. Lethal Midline Granuloma [Unpublished case report]. Philippines: Northern Mindanao Medical Center; 2012

7. Gourin CG, Johnson JT, Selvaggi K. Nasal T-cell lymphoma: case report and review of diagnostic features. Ear Nose Throat J. 2001 Jul; 80(7): 458-60. PMID: 11480303.

8. Alzubaidee A, Ahmed SA. Midline lethal granuloma: Case report and review of literature. Zanco J Med Sci. 2015; 19(1): 935-937. In Press.

9. Mallya V, Singh A, Pahwa M. Lethal midline granuloma. Indian Dermatol Online J. 2013 Jan; 4(1): 37-39. DOI: 10.4103/2229-5178.105469; PMID: 23440011 PMCID: PMC3573451.

10. Yamaguchi M, Kwong Yl, Kim WS, Maeda Y, Hashimoto C, Suh C, et al. Phase II study of SMILE chemotherapy for newly diagnosed stage IV, relapsed, or refractory extranodal natural killer NK/T-cell lymphoma, nasal type: The NK-Cell Tumor Study Group study. J Clin Oncol. 2011 Nov 20; 29(33):4410-4416. DOI: 10.1200/JCO.2011.35.6287; PMID: 21990393.

11. Jaccard A, Gachard N, Marin B, Rogez S, Audrain M, Suarez F, et al. Efficacy of L-asparaginase with methotrexate and dexamethasone (AspaMetDex regimen) in patients with refractory or relapsing extranodal NK/T-cell lymphoma, a phase II study. Blood. 2011 Feb 10; 117(6):18341839. DOI: 10.1182/blood-2010-09-307454; PMID: 21123825

12. Tse E, Kwong YL. How I treat NK/T-cell lymphomas. Blood. 2013 Jun 20; 121(25):4997-5005. DOI: 10.1182/blood-2013-01-453233; PMID: 23652805.

13. Tababi S, Kharrat S, Sellami M, Mamy J, Zainine R, Beltaief N, et al. Extranodal NK/T-cell lymphoma, nasal type: report of 15 cases. Eur Ann Otorhinolaryngol Head Neck Dis. 2012 Jun; 129(3):141-7. DOI: 10.1016/j.anorl.2011.08.004; PMID: 22321911.' 